\title{
¿Es posible atribuir responsabilidad internacio- nal a los Estados acusados de cometer actos terroristas?
}

\author{
JOAQUÍN ALCAIDE FERNÁNDEZ*
}

SUMARIO: I. INTRODUCCIÓN.- II. LAS OBLIGACIONES CONVENCIONALES DE LOS ESTADOS RELATIVAS A LA LUCHA CONTRA EL TERRORISMO.- 1. LOS LÍMITES DE LAS OBLIGACIONES CONVENCIONALES DE LOS ESTADOS RELATIVAS A LA LUCHA CONTRA EL TERRORISMO.- 1.1. LA RELATIVA (IN)DEFINICIÓN DEL TERRORISMO EN GENERAL.- 1.2. LA EXIGENCIA DE UNA TRASCENDENCIA INTERNACIONAL DE LOS ACTOS TERRORISTAS.- 2. EL CONTENIDO NORMATIVO DE LOS TRATADOS ANTITERRORISTAS.- 2.1. LA OBLIGACIÓN DE LOS ESTADOS DE PREVENIR EL TERRORISMO.- 2.2. LA OBLIGACIÓN DE LOS ESTADOS DE REPRIMIR EL TERRORISMO.- III. LAS OBLIGACIONES DE ORIGEN O NATURALEZA NO CONVENCIONAL EN SENTIDO ESTRICTO RELATIVAS A LA LUCHA CONTRA EL TERRORISMO.- IV. RECAPITULACIÓN: LA EXISTENCIA DE UNA VIOLACIÓN DE UNA OBLIGACIÓN INTERNACIONAL... Y LA ATRIBUCIÓN DE LOS ACTOS TERRORISTAS AL ESTADO.- 1. LA ATRIBUCIÓN DE UN COMPORTAMIENTO (EVENTUALMENTE DE ACTOS TERRORISTAS) AL ESTADO.- 2. LA CONSTATACIÓN DE LA VIOLACIÓN DE LAS OBLIGACIONES RELATIVAS A LA PREVENCIÓN Y REPRESIÓN DEL TERRORISMO.- 2.1. EL DOLO Y EL CRITERIO DE LA «DILIGENCIA DEBIDA».- 2.2. LA VIOLACIÓN DE LAS OBLIGACIONES RELATIVAS A LA PREVENCIÓN DEL TERRORISMO.-2.3. LA VIOLACIÓN DE LAS OBLIGACIONES RELATIVAS A LA REPRESIÓN DEL TERRORISMO.- 2.3.1. EN RELACIÓN CON LA EXTRADICIÓN.- 2.3.2. EN RELACIÓN CON EL EJERCICIO DE LA ACCIÓN PENAL Y EL CUMPLIMIENTO DE LAS CONDENAS.

\section{INTRODUCCIÓN}

El interrogante que sirve de título a esta reflexión ${ }^{1}$ — que evoca abiertamente la existencia de un «terrorismo de Estado» en sentido pro$\mathrm{pio}^{2}$ - podría tener, en principio, una respuesta relativamente sencilla:

* Profesor de Derecho Internacional Público y Relaciones Internacionales en la Universidad de Sevilla.

1 Este es el título del tema que se me propuso como contribución a esta edición de la revista Derecho PUCP, publicadaenconmemoración delnoventaaniversariodelaFacultaddeDerechodelaPontificiaUniversidad Católica del Perú, bajo el lema central «Retos para los derechos humanos en el siglo XXI». Para mí ha sido unhonor recibir la invitación para participarenestaconmemoración por partedela doctoraSalmón Gárate, profesora de Derecho Internacional Público de la PUCP, y del doctor Villavicencio Ríos, editor general de la revista. Gracias, querida Liz. Gracias, doctor Villavicencio.

2 Es bien sabido que la expresión «terrorismo de Estado» ha provocado, y sigue provocando, un gran debate, también desde la perspectiva del Derecho internacional. En buena medida, con esa expresión se pretende descalificar, desde la perspectiva del Derecho internacional de la lucha contra el terrorismo, lo ya descalificado desde la perspectiva del Derecho internacional de los derechos humanos, del Derecho internacional humanitarioy delDerechointernacional penal: las violaciones masivasy sistemáticas de los derechos humanos, los crímenes de guerra, los crímenes contra la humanidad, etcétera. Más propiamente, como veremos, los Estados pueden, en efecto, implicarse de un modo u otro, y en diversos grados, en actosyactividadesterroristas, inclusohastaelpuntodequelosactosterroristaspuedanatribuirsedirectae inmediatamente a los Estados; esto último es a lo que me refiero al hablar de un «terrorismo de Estado" en sentido propio. 
sí, por supuesto que es posible atribuir responsabilidad internacional a los Estados acusados de cometer actos terroristas. Y lo es, más precisamente, en términos de responsabilidad de esos Estados por hechos internacionalmente ilícitos, dado que, si los actos terroristas son cometidos por Estados, serían obviamente hechos de tales Estados y entrañarían la violación de sus obligaciones internacionales, sin que en caso alguno exista circunstancia alguna que excluya la ilicitud de tales hechos ${ }^{3}$.

No obstante, en rigor, habría que revelar las dificultades que plantea tal interrogante, al poner en cuestión su misma formulación, y, tras hacer las debidas puntualizaciones y matizaciones, mostrar los argumentos en los que se basan las posibles respuestas a los nuevos interrogantes o a algunos de los nuevos interrogantes conforme con el Derecho internacional (en adelante, DI).

Y es que la referencia a la responsabilidad internacional de los Estados acusados de cometer actos terroristas nos remite obviamente al DI y, particularmente, al DI de la lucha contra el terrorismo, esto es, esencialmente a las obligaciones de los Estados para la prevención y la represión del terrorismo, sea contenidas en diversos tratados internacionales, universales y regionales, sea de otro origen o naturaleza y recogidas en otros instrumentos internacionales, adoptados particularmente en el seno de las Naciones Unidas (resoluciones de la Asamblea General, del Consejo de Seguridad, etcétera); y al DI de la responsabilidad de los Estados por hechos internacionalmente ilícitos, cuyos principios y normas han sido expresados en buena medida por la Comisión de Derecho Internacional (en adelante CDI), en su proyecto de artículos sobre la responsabilidad del Estado por hechos internacionalmente ilícitos, aprobado en segunda lectura en $2001^{4}$ y del que «toma nota» la Asamblea General de las Naciones Unidas en su resolución 56/83, del 12 de diciembre de 2001, en cuyo anexo se reproduce el proyecto de la CDI.

Puntualizar la terminología utilizada en el interrogante me parece importante en dos sentidos: de un lado, porque se me sugiere reflexionar sobre la «posibilidad» de atribuir responsabilidad internacional a los Estados; de otro, porque la reflexión está referida a los Estados «acusados de cometer actos terroristas».

Entiendo, en efecto, que preguntar por la «posibilidad» de atribuir responsabilidad internacional a los Estados acusados de cometer actos terroristas significa preguntar si otros —en realidad, otros Estados- tienen el derecho a invocar esa responsabilidad internacional; en otras palabras, si de un modo u otro los Estados acusados de cometer actos

3 Sobrelaviolación porunEstadodesusobligaciones internacionales relativasalarepresión delterrorismo y las circunstancias excluyentes de la ilicitud, véase más abajo, sin embargo, la nota 70 y el texto al que acompaña.

4 ElproyectodeartículossobreresponsabilidaddelEstadoporhechosinternacionalmenteilícitosfueadoptado por la CDI en su $53^{\circ}$ período de sesiones. Informe de la Comisión de Derecho Internacional, $5^{\circ} \stackrel{\text { período }}{ }$ de sesiones (23 de abril al 1 primero de junio y 2 de julio a 10 de agosto de 2001). Asamblea General. Documentos Oficiales. $56^{\circ}$ período de sesiones. Suplemento $N^{\circ} 10$ (A/56/10), párrafo 77 , pp. 38 y ss. 
terroristas incurren en responsabilidad internacional y otros Estados pueden invocar tal responsabilidad, eventualmente ante un tribunal internacional competente para determinar la existencia de un hecho internacionalmente ilícito que genere responsabilidad internacional para tales Estados acusados de cometer actos terroristas. En apariencia, y a condición de su argumentación conforme con el DI, la respuesta sigue siendo relativamente sencilla, con una precisión: como antes, se diría que sí, que es posible atribuir responsabilidad internacional a los Estados acusados de cometer actos terroristas, y que desde luego el Estado lesionado ${ }^{5}$ puede invocar esa responsabilidad, eventualmente ante un tribunal internacional, siempre que el otro Estado haya aceptado su jurisdicción.

Pero bien pudiera indagarse si no estaríamos ante una de las «violaciones graves de obligaciones emanadas de normas imperativas de DI general» a que se refiere la CDI, por lo que hace al contenido de la responsabilidad, particularmente porque el interrogante alude a la responsabilidad de los Estados por la comisión, directa e inmediatamente, de actos terroristas. Incluso, si son distintas de esas obligaciones y violaciones, si no estaríamos en uno de los supuestos de los que se deriva el derecho de todo Estado que no sea lesionado a invocar la responsabilidad y a tomar medidas contra el Estado responsable, por lo que hace también a los modos de hacer efectiva la responsabilidad internacional de los Estados. Y, al menos en el primer caso, de lo «posible» pasaríamos a lo «necesario», es decir, que al derecho a invocar la responsabilidad se sumarían tal vez las nuevas obligaciones que tendrían todos los Estados frente a violaciones graves de obligaciones emanadas de normas imperativas de DI general ${ }^{6}$.

Más problemas plantea el empleo de la expresión «Estados acusados de cometer actos terroristas». Al ser fieles a la sugerencia que me hizo llegar el editor de esta revista, al parecer la reflexión se ceñiría a los supuestos en los que los actos materiales calificables como «terroristas» son, en sí mismos, directa e inmediatamente hechos de los Estados, es decir, el «terrorismo de Estado» en sentido propio y estricto. En ese y no en otro sentido debe entenderse que los Estados cometan actos terroristas: los actos terroristas son hechos materialmente cometidos por el Estado — a través de los órganos, personas, grupos, entidades, movimientos, etcétera, cuyo comportamiento puede considerarse hecho del Estado según el DI- De ese modo, en principio, se dejaría a un lado la responsabilidad internacional de los Estados por su, podríamos decir, implicación de otro modo en actos y actividades terroristas, y que,

5 LascondicionesparaqueunEstadotenga,comoEstadolesionado, derechoainvocarlaresponsabilidadde otroEstado se contemplan en el artículo 42 del proyecto de artículos de la CDI. Esas condiciones son que la obligación violadaexista:(a)conrelaciónaeseEstadoindividualmente-loquenoeselcasodelostratados multilaterales-; (b) con relación a un grupo de Estados del que ese Estado forme parte, o con relación a la comunidadinternacionalensuconjunto, ylaviolación delaobligación(i)afectaespecialmenteaeseEstado; o (ii)es de tal índole que modifica radicalmente la situación de todos los demás Estados con los que existe esa obligación con respecto al ulterior cumplimiento de esta.

6 Me refiero, en particular, a las obligaciones recogidas en los párrafos 1 y 2, artículo 41, del proyecto de artículos de la CDI.

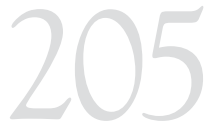

¿ES POSIBLE ATRIBUIR RESPONSABILIDAD INTERNACIONAL A LOS ESTADOS ACUSADOS DE COMETER ACTOS TERRORISTAS? 
en función de la diligencia debida y la efectivamente observada, admite una gradación, sin poder equipararse situaciones y circunstancias tan distintas como la propia autoría, la complicidad por prestar asistencia financiera o logística a terroristas o grupos terroristas (entrenamiento, armas, etcétera), la inducción, la negligencia por la aquiescencia en los actos terroristas o la tolerancia por el ofrecimiento a los terroristas de un «santuario» en su territorio, la incapacidad para controlar a los terroristas que actúan en o a partir de su territorio, o incluso el desconocimiento de la organización, en su territorio, de actividades encaminadas a la comisión de actos terroristas.

Tal vez la verdadera intención de quienes me invitaron a escribir estas páginas no fuera reducir la reflexión a la sola circunstancia de la comisión por un Estado de actos terroristas — esto es, la propia autoría—, y por eso me ocuparé más generalmente de la responsabilidad internacional de los Estados por su implicación en actos y actividades terroristas — no solo del «terrorismo de Estado»..._, incluida su responsabilidad en relación con el hecho de otro Estado, si bien trataré de explorar particularmente si es posible, por qué, cuándo y en qué circunstancias, invocar la responsabilidad internacional de un Estado por la comisión de actos terroristas.

Pero antes debo suscitar otros problemas que plantea aquella expresión («Estados acusados de cometer actos terroristas»), particularmente porque pretender la exigencia de responsabilidad internacional de los Estados que son «acusados» de cometer actos terroristas nos reconduce a otros interrogantes. Lo de menos es que la expresión «Estado acusado» sea un tanto ajena al DI, porque parece evocar la existencia de un juicio ante un tribunal en el que se dirimen responsabilidades penales que difícilmente pueden exigirse a los Estados. En su proyecto de artículos, la propia CDI utiliza precisamente la expresión «atribuir» un hecho a un Estado, y no «imputar» un hecho a un Estado, para aliviar de tintes penales la responsabilidad internacional de los Estados (aunque la coherencia de esa estrategia no se completó sino en la segunda lectura, cuando la CDI suprimió del proyecto de artículos cualquier referencia a la distinción entre «crímenes» y «delitos» de los Estados, que todavía se recogía en el proyecto de artículos aprobado por la CDI en primera lectura, en 1996).

Lo que importa es, sobre todo, que en este punto habría que rectificar mi aparentemente sencilla respuesta al interrogante principal y decir ahora «no, no es posible invocar la responsabilidad internacional a los Estados simplemente 'acusados' de cometer actos terroristas». Y al ofrecer esta respuesta prescindo de otras cuestiones que no la modificarían - por ejemplo, quién o quiénes «acusan» y ante quién o quiénes-y me concentro en la cuestión realmente determinante: los Estados incurren en responsabilidad internacional por la comisión de actos terroristas siempre que esos hechos, ilícitos en cualquier circunstancia por supuesto -al menos siempre que sean calificables realmente como «terroristas», 
porque la (in)definición de terrorismo en DI importa-, sean atribuibles al Estado y, desde luego, así se determine objetivamente.

Por difícil que sea la prueba, no es posible exigir responsabilidad internacional a los Estados por simples «acusaciones» si no están fundadas en el DI, es decir, si no está probado o es notorio que el Estado es responsable conforme con el DI. Una cosa es —o son- la(s) pretensión(es) subjetiva(s) de un Estado o de un grupo de Estados, y otra cosa es que exista una determinación objetiva de que un Estado haya cometido actos terroristas. Si bien no siempre existe, o más bien generalmente no existe, la determinación por parte de un órgano — judicial o arbitral— imparcial con competencia y autoridad para formular tal determinación objetiva, la posibilidad de invocar la responsabilidad internacional de los Estados implicados en actos y actividades terroristas no deja de depender de la existencia del hecho internacionalmente ilícito que genera esa responsabilidad. Esta es una de las principales dificultades que plantea la estructura social descentralizada y escasamente institucionalizada en la que se basa el DI.

En definitiva, exploraré las posibilidades que, en términos de generación de la responsabilidad internacional, abre la implicación de los Estados en actos y actividades terroristas, particularmente por la comisión de actos terroristas. Nos limitaremos al estudio del fundamento de la responsabilidad internacional de esos Estados, sin entrar a estudiar el contenido y los modos de hacer efectiva esa responsabilidad?

En este sentido, la responsabilidad internacional de un Estado por un hecho ilícito es generada por la conjunción de dos elementos: que el comportamiento consistente en una acción u omisión sea atribuible al Estado según el DI y que dicho comportamiento constituya una violación de una obligación internacional del Estado ${ }^{8}$. La calificación del hecho del Estado como internacionalmente ilícito se rige por el DI, al margen de lo que disponga el Derecho interno 9 , y tampoco importa el origen o la naturaleza - esencialmente convencional o consuetudinaria, pero cada vez más también su origen puede encontrarse en decisiones del Consejo de Seguridad - de la obligación violada ${ }^{10}$. Basta, por tanto, examinar los comportamientos que serían atribuibles, según el DI, a los Estados y contrastar la conformidad o disconformidad de esos hechos

7 Estareflexiónnopuedesinosertributariadeaquellaotraquepubliquébajoeltítulo Lasactividadesterroristas ante el Derecho internacional contemporáneo (Madrid: Tecnos, 2000), suscitada en buena medida por los trabajos de los profesores J.A. Carrillo Salcedo y J.A. Frowein, como directores de la sesión de 1988 del CentrodeEstudioselnvestigaciones delaAcademiadeDerecholnternacionaldeLaHaya, dedicadaaltema de «Los aspectos jurídicos del terrorismo internacional» (Les aspects juridiques du terrorisme international) The Legal Aspects of International Terrorism. Dordrecht: Martinus Nijhoff Publishers, 1989), y se inspira en losprincipiosynormasdelDIrecogidosenlaprimeraparte(«ElhechointernacionalmenteilícitodelEstado», artículos 1 a 27), además de dejar a un lado los principios y normas del DI recogidos en la segunda y tercera partes del proyecto de artículos de la CDI sobre responsabilidad del Estado por hecho internacionalmente ilícito ("Contenido de la responsabilidad internacional del Estado», artículos 28 a 41, y «Modos de hacer efectiva la responsabilidad internacional del Estado", artículos 42 a 54).

8 Artículos 1 y 2 del proyecto de artículos de la CDI.

9 Artículo 3 del proyecto de artículos de la CDI.

10 Artículo 12 del proyecto de artículos de la CDI.

¿ES POSIBLE ATRIBUIR RESPONSABILIDAD INTERNACIONAL A LOS ESTADOS ACUSADOS DE COMETER ACTOS TERRORISTAS? 
con lo que de esos Estados exigen las obligaciones internacionales relativas a la prevención y represión del terrorismo que les vinculan.

Estas obligaciones han tenido una evolución normativa distinta desde la perspectiva de su origen o naturaleza y, por tanto, de su eficacia jurídica, general o relativa: la obligación de prevenir el terrorismo se consideró ya a principios del siglo XX como una obligación de DI general o consuetudinario — como atestiguan la resolución del 10 de diciembre 1934 del Consejo de la Sociedad de Naciones y, aunque la Convención nunca entró en vigor, el texto del artículo 1.1 de la I Convención de Ginebra de 1937-, mientras que era necesario precisar las normas relativas a la represión o sanción del terrorismo, y esencialmente a tal fin se han adoptado los diversos tratados internacionales.

\section{LAS OBLIGACIONES CONVENCIONALES DE LOS ESTADOS RELATIVAS A LA LUCHA CONTRA EL TERRORISMO}

La determinación de la existencia de esas obligaciones internacionales y de la vinculación de los Estados es relativamente sencilla, desde luego cuando las obligaciones se contienen en tratados internacionales: existen muchos tratados antiterroristas adoptados tanto en un ámbito universal $\left(\mathrm{ONU}^{11}\right.$, $\mathrm{OACI}^{12}$, OIEA $\left.{ }^{13} \mathrm{Y}_{\mathrm{OMI}}{ }^{14}\right)$ como en un ámbito regional $\left(\mathrm{OEA}^{15}\right.$, Consejo de Europa ${ }^{16}$ y UE ${ }^{17}$, Asociación del Sur de Asia para la Cooperación

11 Convención sobre la Prevención y el Castigo de Delitos contra Personas Internacionalmente Protegidas, inclusivelosagentesdiplomáticos, hechoen NuevaYorkel14dediciembrede1973;ConvenciónInternacional contralaTomade Rehenes, hechaen Nueva Yorkel17 dediciembre de 1979; Conveniolnternacional para la Represión delos Atentados Terroristas cometidoscon Bombas, hechoen Nueva Yorkel15dediciembrede 1997; ConvenioInternacionalparalaRepresióndelaFinanciación delTerrorismo, hechoen Nueva Yorkel9 dediciembrede1999; yConveniolnternacional paralaRepresióndelos Actos de TerrorismoNuclear, hecho en Nueva York el 14 de septiembre de 2005.

12 La-prevencióny-represióndelosdelitoscontralaseguridaddelaaviacióncivilinternacionalsecontempla enel Convenio sobre las Infracciones y Ciertos Actos cometidos a bordo de las Aeronaves, hechoen Tokio el 14 de septiembre de 1963; el Convenio para la Represión del Apoderamiento llícito de Aeronaves, hecho en La Haya el 16 de diciembre de 1970; el Convenio para la Represión de Actos llícitos contra la Seguridad de la Aviación Civil, hecho en Montreal el 23 de septiembre de 1971 y su Protocolo Complementario sobre la Represión de los Actos llícitos de Violencia en los Aeropuertos que presten Servicio a la Aviación Civil Internacional, hecho en Montreal el 24 de febrero de 1988; y el Convenio sobre la Marcación de Explosivos Plásticos para los fines de Detección, hecho en Montreal el primero de mayo de 1991.

13 Convención sobre la Protección Física de los Materiales Nucleares, hechoen Viena el 3 de marzo de 1980, y su enmienda de 2005.

14 Convenio para la Represión de Actos llícitos contra la Seguridad de la Navegación Marítima y Protocolo paralaRepresión de Actos llícitoscontralaSeguridad delasPlataformas Fijasemplazadasen laPlataforma Continental, hechos en Roma el 10 de marzo de 1988, así como los protocolos de 2005 tanto al convenio como al protocolo de 1988.

15 ConvenciónparaPrevenirySancionarlosActosdeTerrorismoconfiguradosenDelitoscontralasPersonas ylaExtorsiónconexacuandoéstos [sic]tenganTrascendencialnternacional, hechaenWashingtonD.C.el2 defebrerode1971,y ConveniolnteramericanocontraelTerrorismo, hechoen Bridgetown, Barbados, el6de marzo de 2002.

16 Convención Europea para la Represión del Terrorismo, adoptada en Estrasburgo el 27 de enero de 1977,y su protocolo de enmienda de 2003, así como las convenciones de Varsovia, de 16 de mayo de 2005, para laPrevencióndelTerrorismoyrelativaalBlanqueo,Seguimiento,Embargoy DecomisodelosProductosdel Delito y a la Financiación del Terrorismo.

17 Antes de la creación de la Unión Europea (UE), en 1992, en el marco de los trabajos del «Club de Berna», desde 1968 o del "Grupo TREV|» desde 1975, y precisamente para amortiguar los efectos negativos que pudieran derivarse del hecho de que algunos Estados miembros no fueran parte en la Convención de Estrasburgode1977,odequesiendoparteformularan lareservacontempladaensuartículo13,los Estados miembros de las comunidades europeas firmaron un acuerdoen Dublín, en 1999, quenuncaentróen vigor. Los Ilamados «Estados de Schengen» tampoco avanzaron mucho en este sentido. El Tratado de la Unión 
Regional [SAARC por sus siglas en inglés] ${ }^{18}$, Liga de Estados Árabes ${ }^{19}$, $\mathrm{CEI}^{20}$, OIC ${ }^{21}$, OUA/UA ${ }^{22}$ y la Organización de Cooperación de Shangai [SCO por sus siglas en inglés] ${ }^{23}$ ). Otros tratados internacionales también contemplan la prohibición de la toma de rehenes y del terrorismo (los Convenios de Ginebra de 1949 y sus protocolos adicionales de $1977^{24}$ ), y puede derivarse de dichos tratados y de otras disposiciones - como los estatutos de los tribunales penales internacionales para la ex Yugoslavia (TIPY) y para Ruanda (TIPR), del tribunal de Sierra Leona, etcétera, o de la Corte Penal Internacional (CPI) - que el terrorismo es un crimen de guerra - en este sentido, por ejemplo, el caso Fiscal c. Stanislav Galić, No. IT-98-29, sentencia y opinión de la Sala de Juicios del 5 de diciembre de 2003 y sentencia de la Sala de Apelaciones de 30 de noviembre de 2006 - o un crimen contra la humanidad.

En cualquier caso, para determinar la existencia de esas obligaciones internacionales y la vinculación de los Estados, tan solo habría que comprobarse la vigencia del tratado en general y para cada Estado en particular.

\section{Los límites de las obligaciones convencionales de los Estados relativas a la lucha contra el terrorismo}

Esos tratados tienen, no obstante, unos límites — distintos del derivado del principio básico aplicable a todo tratado: su efecto relativo- que no deben desconocerse. Los tratados normalmente se refieren a delitos considerados manifestaciones del terrorismo (internacional), esto es, a delitos en particular y no al terrorismo o a los «actos terroristas» en general, y además se refieren a delitos de terrorismo con una trascendencia internacional.

Europea(TUE) adoptadoen Maastrichtestableció las bases para una cooperación en asuntos de justiciae interiormásestrecha(en particularlosartículosK.1yK.3), peroconmatices(artículoK.2); posteriormente,a partir del Convenio relativoa la Extradición entre los Estados Miembros de la Unión Europea, adoptado por el Consejo sobre la base del artículo K.3(2)(c) del TUE, y de los tratados de Ámsterdam y Niza, en el ámbito ya de la cooperación policial y judicial en materia penal y de la política exterior y de seguridad común, se ha avanzado muchoen la luchacontrael terrorismo, particularmentetrasel 11 de septiembre de 2001 yel 11 de marzode2004(«euroorden», definicióncomún,etcétera), sinque,noobstante,sehayandejadoatrástodos los obstáculos.

18 Convención Regional para la Represión del Terrorismo, firmada en Katmandú el 4 de noviembre de 1987, y su protocolo adicional, hecho en Islamabad el 6 de enero de 2004.

19 Convención para la Represión del Terrorismo, firmada en El Cairo el 22 de abril de 1998.

20 Tratadorelativoala Cooperaciónentre los Estados Miembros delaComunidaddeEstados Independientes en el Combate contra el Terrorismo, hecho en Minsk el 4 de junio de 1999.

21 ConvencióndelaOrganización delaConferencialslámicaparaelCombatecontraelTerrorismolnternacional, adoptada en Ouagadougou el primero de julio de 1999.

22 Convención de la Organización para la Unión Africana (luego Unión Africana) relativo a la Prevención y Combate contrael Terrorismo, adoptadoen Argeliael 14 de julio de 1999y su Protocolo de Addis Abeba, del 8 de julio de 2004.

23 ConvenciónparalaLuchacontraelTerrorismo,elSeparatismoyelExtremismo,adoptadaenShanghaiel15 de junio de 2001.

24 En particular, en el artículo 3 común a los convenios de Ginebra o los artículos 33 y 34 de la IV Convención, así como el artículo 51.2 del Protocolo Adicional I y el artículo 13.2 del Protocolo Adicional II.

¿ES POSIBLE

ATRIBUIR RESPONSABILIDAD INTERNACIONAL A LOS ESTADOS ACUSADOS DE COMETER ACTOS TERRORISTAS? 


\subsection{La relativa (in)definición del terrorismo en general}

Al no existir aún el suficiente consenso para aprobar el proyecto de convención general sobre el terrorismo que se negocia en el seno del comité ad-hoc creado mediante la resolución 51/210 de la Asamblea General de las Naciones Unidas, del 17 de diciembre de 1996, los tratados universales contemplan delitos concretos (contra la aviación civil internacional, contra personas internacionalmente protegidas, la toma de rehenes, etcétera) y, aun cuando a veces los comportamientos comprendidos son más generales, hay una remisión a los delitos contemplados en otros tratados. Por ejemplo, la financiación del terrorismo se contempla en el Convenio de Nueva York de 1999 y remite en su artículo 2.1(a) a los delitos comprendidos en el ámbito de uno de los tratados enumerados en un anexo y tal como están definidos en esos tratados ${ }^{25}$; lo mismo o casi lo mismo ocurre con los tratados regionales (por ejemplo, los artículos 1 y 2 del Convenio Europeo para la Represión del Terrorismo y el artículo 1 del Convenio Europeo para la Prevención del Terrorismo, el artículo 2 de la Convención Interamericana contra el Terrorismo, el artículo I de la Convención Regional SAARC y el artículo 4 de su protocolo adicional, el artículo 1.3 de la Convención Árabe, el artículo 1 del Tratado de la CEI o el artículo 1.4 de la Convención de la OCI ${ }^{26}$.

Es cierto que algún tratado universal y muchos de los tratados regionales contienen otras disposiciones que permiten extender su aplicación más allá de los delitos definidos en los tratados universales. En este sentido, el Convenio de Nueva York de 1999 considera «financiación del terrorismo» como la provisión o recolección de fondos para cometer no solo un acto que constituya un delito comprendido en el ámbito de los tratados enumerados en el anexo, sino también:

[...] cualquier otro acto destinado a causar la muerte o lesiones corporales graves a un civil o a cualquier otra persona que no participe directamente en las hostilidades en una situación de conflicto armado, cuando el propósito de dicho acto, por su naturaleza o contexto, sea intimidar a una población u obligar a un gobierno o a una organización internacional a realizar un acto o a abstenerse de hacerlo.

La intención o propósito terrorista, que ya había sido identificado en la I Convención de Ginebra de 1937 para la Prevención y Represión del Terrorismo, adoptada en el seno de la Sociedad de Naciones, no se recoge en muchos tratados universales; en realidad, en ninguno, excepto en la Convención de Nueva York de 1979, que define la toma de rehenes en función del fin «de obligar a un tercero, a saber, un Estado, una organización internacional intergubernamental, una persona natural o jurídica o un grupo de personas, a una acción u omisión como condición 
explícita o implícita para la liberación del rehén». Otros tratados universales (los convenios de Nueva York de 1997 y 2005) recogen esa intención o propósito terrorista para subrayar que no puedan justificarse en circunstancia alguna y que sean sancionados con penas acordes a su gravedad, particularmente los actos criminales comprendidos en su ámbito «que obedezcan a la intención o el propósito de crear un estado de terror en la población en general, en un grupo de personas o en determinadas personas» ${ }^{27}$. Nada de esto puede extrañar si, además, tenemos en cuenta que ninguno de los tratados universales adoptados antes del Convenio de Nueva York de 1997 incluyeron siquiera el término «terrorismo» o «terrorista» (solo a través de ciertas referencias en las resoluciones adoptadas por la Asamblea General de las Naciones Unidas podía afirmarse que, en realidad, todos los delitos comprendidos en dichos tratados eran manifestaciones del terrorismo internacional).

Los tratados regionales suelen, como decía, contener otras disposiciones que permiten extender su aplicación más allá de los delitos definidos en los tratados universales, a veces en una compleja estrategia de ir mucho más allá... y, al mismo tiempo, de no llegar. Ejemplo de lo primero: la alusión en 1977 —antes, por tanto, de la adopción del Convenio de Nueva York de 1997- en el Convenio Europeo para la Represión del Terrorismo a «delitos que impliquen la utilización de bombas, granadas, cohetes, armas de fuego automáticas, o cartas o paquetes con explosivos ocultos, en los casos en que dicha utilización represente un peligro para las personas» (artículo 1(e)) o a "cualquier acto grave de violencia [...] que esté dirigido contra la vida, la integridad corporal o la libertad de las personas» o a «cualquier acto grave contra los bienes [...], cuando dicho acto haya creado un peligro colectivo para las personas» (artículo 2), así como la toma en consideración del carácter de especial gravedad de una infracción, incluidas las circunstancias de haber creado un peligro colectivo para la vida, la integridad corporal o la libertad de las personas, o de haber afectado a personas ajenas a los móviles que la inspiraron, o de que para su realización se utilizaran medios crueles o perversos (artículo 13.1). También la Convención Regional SAARC (artículos I (d) y (e), y artículo II), el Tratado de la CEI (artículo 1) y la Convención de Shanghai (artículo 1.1) contienen amplias definiciones del terrorismo o delitos o actos terroristas que incluyen otros delitos no comprendidos en los tratados universales.

Ejemplo de la compleja estrategia de ir mucho más allá de los delitos definidos en los tratados universales, y al mismo tiempo de no llegar, son la Convención Árabe de 1998, la Convención de la OUA y la Convención de la OCI: todas contienen una definición amplia de «terrorismo» y de «delito terrorista» (artículo 1) ${ }^{28}$, en las que por cierto se incluye también a la piratería — expresamente en el artículo 1 de la Convención

¿ES POSIBLE ATRIBUIR RESPONSABILIDAD INTERNACIONAL A LOS ESTADOS ACUSADOS DE COMETER ACTOS TERRORISTAS? 
Árabe y de la Convención de la OCI y, en cierta medida, en el anexo de la Convención de la OUA ${ }^{29}$ - y, al mismo tiempo, excluyen de los delitos terroristas los casos de lucha por cualesquiera medios, incluso la lucha armada, de acuerdo con los principios del DI, para la liberación y la autodeterminación contra la ocupación extranjera y la agresión (artículo 2 de la Convención Árabe), o contra el colonialismo, la ocupación, la agresión y la dominación por fuerzas extranjeras (artículo 3.1 de la convención de la OUA), o contra la ocupación extranjera, la agresión, el colonialismo e incluso la hegemonía (artículo 2(a) de la Convención de la OCI).

La exclusión de las luchas de liberación nacional del ámbito de aplicación de los tratados antiterroristas puede abundar en una confusión que se suscitó, particularmente, a raíz de la inclusión de dichas luchas entre los conflictos armados de carácter internacional en el Protocolo II Adicional a los Convenios de Ginebra y de la redacción del artículo 12 de la Convención de Nueva York de 1979. En realidad, si esas luchas deben conducirse «de acuerdo con los principios del DI», como reconocen esos propios tratados regionales, debe admitirse que en caso alguno podrían conllevar la comisión de actos y actividades terroristas, pues el terrorismo está igualmente prohibido, como dijimos, en el DI humanitario. Pero, con seguridad, esta no es la interpretación que de la coherencia del marco jurídico internacional para la lucha contra el terrorismo hacen quienes, de un lado, no consideran legítimas esas luchas (armadas) de liberación nacional $-y$, por tanto, tampoco son proclives a su calificación como conflictos armados de carácter internacional, por lo que esa calificación trae consigo en relación con el derecho de los combatientes a recurrir a la violencia y con el estatuto que como principio han de reconocérsele al caer en poder del enemigo- y, de otro, quieren legitimar cualquier recurso a la violencia por quienes luchan por la liberación y la autodeterminación, incluido el terrorismo. Eso sí, siempre que esa liberación y autodeterminación no se proclame frente a tales Estados: la Convención Árabe no considera aplicable la exclusión de las luchas de liberación nacional del ámbito de los tratados antiterroristas respecto de cualquier acto que sea perjudicial para la integridad territorial de cualquier Estado árabe (artículo 2).

Por lo demás, esos y otros tratados regionales antiterroristas se preocupan igualmente por las insurrecciones y el mercenarismo ${ }^{30}$, la estabilidad, la integridad territorial, la unidad política o la soberanía de Estados independientes ${ }^{31}$, o, junto con el terrorismo, comprenden el separatismo y el extremismo ${ }^{32}$.

29 Esta convención de la OUA también incluye en el anexo a la Convención sobre la Prohibición del Empleo, Almacenamiento, Produccióny Transferencia de Minas Antipersonaly sobresu Destrucción, adoptadaen Ottawa el 18 de septiembre de 1997.

$30 \mathrm{EI}$ artículo 3(a)(iii) de la Convención de la OUA y el preámbulo y artículo 3(e) de su protocolo, respectivamente.

31 Artículo 1.2 de la Convención de la OCI.

32 En este sentido, la Convención de Shanghai. 


\subsection{La exigencia de una trascendencia internacional de los actos terroristas}

Por otra parte, a diferencia de los tratados regionales — salvo por la remisión que esos tratados eventualmente hacen a los tratados universales-, los tratados universales se ocupan exclusivamente de los distintos delitos terroristas cuando tienen trascendencia internacional: tomando nuevamente el ejemplo del Convenio de Nueva York de 1999, en efecto, su artículo 3 dispone que:

El presente Convenio no será aplicable cuando el delito se haya cometido en un solo Estado, el presunto delincuente sea nacional de ese Estado y se encuentre en el territorio de ese Estado y ningún otro Estado esté facultado para ejercer la jurisdicción con arreglo a lo dispuesto en el párrafo 1 o 2 del artículo 733 , con la excepción de que serán aplicables a esos casos, cuando corresponda, las disposiciones de los artículos 12 a $18^{34}$.

Esta es, a mi juicio, la única distinción relevante entre actos de terrorismo - que en realidad no es una distinción entre actos de terrorismo y, además, es más precisa que la distinción entre terrorismo internacional y terrorismo interno-, la cual lo único que pretende es racionalizar el Derecho aplicable, esto es, distinguir cuándo el Derecho interno es suficiente para la prevención y la represión de un acto terrorista y cuándo es necesario que concurra el DI.

En todo caso, es reseñable la previsión de que difícilmente el Derecho interno es suficiente y, por eso, de que siempre se apliquen o puedan aplicarse las disposiciones relativas a la asistencia judicial recíproca, a la exclusión de la calificación de cualquiera de esos delitos como delito fiscal o delito político a efectos de la extradición o la asistencia judicial recíproca, la cláusula humanitaria, el traslado de personas detenidas o que cumplen condena, el trato a los detenidos y a la prevención de los delitos.

\section{El contenido normativo de los tratados antiterroristas}

Como avancé anteriormente, desde principios del siglo XX existía un amplio consenso conforme con el cual se reconocía que el DI acoge una obligación general de prevenir el terrorismo; por eso, los tratados internacionales adoptados posteriormente, empezando por las convenciones de Ginebra de 1937, trataban de precisar las normas relativas a la represión o sanción del terrorismo.

33 Esos párrafos 1 y 2 del artículo 7 contemplan las bases conforme con las cuales cada Estado parte debe o puedeestablecersujurisdicción: Estadoencuyoterritoriosecometeelacto, Estadodelpabellón delbuque o de matrícula de la aeronave a bordo de la cual se comete el acto, Estado de la nacionalidad del autor, etcétera.

34 Disposiciones relativas a la asistenciajudicial recíproca, la exclusión de lacalificación como delitofiscalo delitopolíticoaefectos delaextradiciónolaasistenciajudicial recíproca,lacláusulahumanitaria,eltraslado de personas detenidas o que cumplen condena, el trato a los detenidos y prevención de los delitos.

¿ES POSIBLE ATRIBUIR RESPONSABILIDAD INTERNACIONAL A LOS ESTADOS ACUSADOS DE COMETER ACTOS TERRORISTAS? 
La interpretación del contenido y alcance de esas obligaciones no siempre es fácil, particularmente cuando se exige un comportamiento determinado cuyo resultado está en función, en buena media, del criterio de la diligencia debida; pero desde luego la interpretación y determinación del exacto contenido y alcance de esas obligaciones es imprescindible para determinar que existe una violación de una de dichas obligaciones, esto es, que un hecho de un Estado «no está en conformidad con lo que de él exige esa obligación» ${ }^{35}$. La dificultad se agudiza porque las obligaciones se acompañan de derechos. Es sintomático de esas dificultades que, a raíz del atentado terrorista contra el vuelo 103 de la aerolíneas Pan Am, el 21 de diciembre de 1988, que hizo explosión sobre la localidad escocesa de Lockerbie, y las posteriores exigencias dirigidas a Libia por el Consejo de Seguridad, fuera precisamente Libia la que demandara ante la Corte Internacional de Justicia (CIJ) a los Estados Unidos de América y al Reino Unido de Gran Bretaña e Irlanda del Norte —que, a continuación, llevaron al Consejo de Seguridad, por su parte, a interferir en el proceso judicial—.

\subsection{La obligación de los Estados de prevenir el terrorismo}

El objeto y propósito de muchos de los tratados antiterroristas es, esencialmente, y a veces exclusivamente, la represión del terrorismo. Muchos recogen en su título expresamente el término «represión» del terrorismo, y pocos aluden a la «prevención» ${ }^{36}$, pero, ciertamente, por regla general hay alguna disposición relativa a la prevención. Por ejemplo, el Convenio de Nueva York de 1999 — que, cabe recordar, es «para la represión de la financiación del terrorismo»- incluye una exhaustiva disposición relativa a la obligación de los Estados parte de cooperar en la prevención de delitos comprendidos y, en particular, para impedir que se prepare en sus respectivos territorios la comisión de esos delitos, tanto dentro como fuera de ellos (artículo 18) ${ }^{37}$.

35 Artículo 12 del proyecto de artículos de la CDI.

36 Delostratadosuniversales,sololaConvencióndeNuevaYorkde1973habladeprevención,mientrassolola Convención de Nueva Yorkde 1979no hablanideprevención nide represión. Entre lostratados regionales, hablan de la prevención el Convenio de la OEA de 1971 yel nuevo Convenio Europeo de 2005, mientras que la mayoría no mencionan ni la prevención ni la represión.

37 Esa disposición reza así: «1. Los Estados Partes cooperarán en la prevención de los delitos enunciados en el artículo 2, tomando todas las medidas practicables, entre otras, adaptando, de ser necesario, su legislación nacional para impedir que se prepare en sus respectivos territorios la comisión de esos delitos tantodentrocomofueradeellos, incluidas:a)Medidasparaprohibirensusterritorioslasactividadesilegales de personas y organizaciones que promuevan, instiguen, organicen o cometan a sabiendas los delitos enunciados en elartículo 2; b) Medidas que exijan que las instituciones financieras y otras profesiones que intervengan en las transacciones financieras utilicen las medidas más eficientes de que dispongan para la identificación de sus clientes habituales u ocasionales, así como de los clientes en cuyo interés se abran cuentas, y presten atención especial a transacciones inusuales o sospechosas y reporten transacciones que se sospeche provengan de una actividad delictiva. A tales efectos, los Estados Partes considerarán: i) Adoptar reglamentaciones que prohíban la apertura de cuentas cuyos titulares o beneficiarios no estén ni puedan seridentificados, asícomomedidas paravelarporqueesas instituciones verifiquen laidentidadde lostitulares reales deesastransacciones;ii)Con respectoa la identificación de personas jurídicas, exigira lasinstitucionesfinancierasque,cuandoseanecesario,adoptenmedidasparaverificarlaexistenciajurídica ylaestructura del clientemediantela obtención, de un registropúblico, delclienteodeambos, de pruebade laconstitucióndelasociedad,incluidainformaciónsobreelnombredelcliente,suformajurídica,sudomicilio, susdirectoresylasdisposicionesrelativasalafacultaddelapersonajurídicaparacontraerobligaciones;iii) Adoptarreglamentacionesqueimponganalasinstitucionesfinancieraslaobligacióndereportarconprontitud alasautoridadescompetentestodatransaccióncompleja,demagnitudinusualy todas laspautasinusuales detransaccionesquenotengan, alparecer, unafinalidadeconómicauobviamentelícita,sintemordeasumir 
Los tratados que aluden en su título a la prevención (la Convención de la OEA de 1971, la Convención de la OUA o el I Convenio Europeo de 2005) y los que no aluden en su título ni a la prevención ni a la represión (en el ámbito universal, solo la Convención de Nueva York de 1979 y, en el regional, el Tratado de la CEI, las convenciones de la OCI y de Shanghai, el Convenio de la OEA de 2002 y el II Convenio Europeo de 2005) suelen ser más profusos en las obligaciones relativas a la prevención.

De lo que no hay duda, va de suyo podría decirse, es que las obligaciones relativas a la prevención a cargo de los Estados partes que formulan los distintos tratados, así como todas las obligaciones relativas a la represión, presuponen y parten de una primera y muy principal obligación a cargo igualmente de los Estados: no cometer los actos terroristas en cuestión. No obstante, algún que otro tratado (regional) no da por supuesta esa obligación y la formula expresamente; así, en el artículo 3 de la Convención Árabe, los Estados parte comienzan por afirmar su «compromiso de no organizar, financiar o cometer actos terroristas o ser cómplices en estos en forma alguna»; y también los Estados parte en la Convención de la OUA recogen, en su artículo 4.1, su compromiso de «abstenerse de cualesquiera actos dirigidos a organizar, apoyar, financiar, cometer o incitar a cometer actos terroristas $[\ldots]$...

En definitiva, esos tratados no hacen sino expresar, precisar y adaptar aquella obligación general de DI relativa a la prevención del terrorismo que, entre otras, se expresó también en la declaración sobre los principios de DI referentes a las relaciones de amistad y a la cooperación entre los Estados, de conformidad con la Carta de las Naciones Unidas, anexa a la resolución 2625 (XXV) de la Asamblea General de las Naciones Unidas, del 24 de octubre de 1970, en relación con los principios de abstención del recurso a la amenaza o al uso de la fuerza ${ }^{38}$ y de no intervención en los asuntos que son de jurisdicción interna de otros Estados ${ }^{39}$,

responsabilidadpenalocivilporquebrantaralgunarestricciónenmateriadedivulgacióndeinformación,si reportan sus sospechas de buena fe; iv) Exigir a las instituciones financieras que conserven, por lo menos durantecincoaños, todoslosdocumentosnecesariossobrelastransaccionesefectuadas, tantonacionales comointernacionales.2.LosEstados Partescooperaránademásenlaprevencióndelosdelitosenunciados enelartículo2considerando:a)Adoptarmedidasdesupervisión,queincluyan, porejemploelestablecimiento de un sistema de licencias para todas las agencias de transferencia de dinero; b) Aplicar medidas viables a findedescubrirovigilareltransportetransfronterizofísicodedineroenefectivoeinstrumentosnegociables alportador,sujetasasalvaguardiasestrictasquegaranticenunautilizaciónadecuadadelainformaciónysin que ello obstaculice en modo alguno la libre circulación de capitales. 3. Los Estados Partes reforzarán su cooperaciónenlaprevencióndelosdelitosenunciadosenelartículo2medianteelintercambiodeinformación precisa y corroborada, de conformidad con las disposiciones de su legislación nacional, y la coordinación de medidas administrativas y de otra índole adoptadas, según proceda, para impedir que se cometan los delitos enunciados en el artículo 2, especialmente para: a) Establecer y mantener vías de comunicación entresusorganismosyservicioscompetentesafindefacilitarelintercambioseguroyrápidodeinformación sobre todos los aspectos de los delitos enunciados en el artículo 2; b) Cooperar en la investigación de los delitos enunciados en el artículo 2 en lo que respecta a: i) La identidad, el paradero y las actividades de las personas con respecto a las cuales existen sospechas razonables de que participan en dichos delitos; ii) El movimiento de fondos relacionados con la comisión de tales delitos. 4. Los Estados Partes podrán intercambiar información por intermedio de la Organización Internacional de Policía Criminal (Interpol)».

38 «Todo Estado tiene el deber de abstenerse de organizar, instigar, ayudar o participar [...] en actos de terrorismo en otro Estado, o de consentir actividades organizadas dentro de su territorio encaminadas a la comisión de dichos actos, cuando [tales] actos [...] impliquen el recurrir a la amenaza o al uso de la fuerza".

39 «Todos los Estados deberán [...] abstenerse de organizar, apoyar, fomentar, financiar, instigar o tolerar actividades [...] terroristas encaminadas a cambiar por la violencia el régimen de otro Estado [...]».

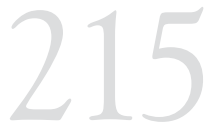

¿ES POSIBLE ATRIBUIR RESPONSABILIDAD INTERNACIONAL A LOS ESTADOS ACUSADOS DE COMETER ACTOS TERRORISTAS? 
y en otras muchas resoluciones de la Asamblea General sobre medidas para eliminar el terrorismo internacional y del Consejo de Seguridad sobre determinados actos terroristas o sobre los actos terroristas en general, como amenazas a la paz y la seguridad internacionales.

La comisión de actos terroristas por un Estado, lógicamente, no está en conformidad con lo que de él exige la obligación de prevención del terrorismo. Pero la prevención no solo exige un razonable sistema de vigilancia, protección y control, sino que también exige que los Estados dispongan lo necesario para que sus Derechos internos permitan, llegado el caso, la sanción de los responsables de los actos terroristas y que, sin haberse podido prevenir su comisión, los responsables sean efectivamente sancionados. Y la violación de las obligaciones relativas a la represión del terrorismo implica, de un modo u otro, a los Estados en esos actos terroristas y, en último extremo, si la violación es grave, podría resultar en la atribución misma de los actos terroristas al Estado.

\subsection{La obligación de los Estados de reprimir el terrorismo}

En lo que respecta a la represión de los actos terroristas, los tratados antiterroristas se vertebran en torno a una obligación principal (extraditar o juzgar) y a unas obligaciones accesorias tendentes a hacer posible esa otra principal (tipificar, punir y establecer la jurisdicción; suministrar la información relativa a las circunstancias de los actos terroristas y a los presuntos terroristas; detener a los presuntos terroristas e investigar preliminarmente los hechos; prestar asistencia judicial en materia penal, y rendir cuentas).

Con el tiempo, los tratados internacionales han ido precisando, más y más, las obligaciones a cargo de los Estados parte, con lo que han reducido el margen de discrecionalidad que ha, tradicionalmente, permitido a los Estados una alternativa ante la extradición o el enjuiciamiento: no hacer nada. Sincrónicamente, los tratados regionales han sido generalmente más exigentes que los universales — con la salvedad, ciertamente, de la exclusión en algunos tratados antiterroristas de su aplicación a las luchas de liberación nacional—; diacrónicamente, los tratados posteriores, universales y regionales, son más exigentes que los tratados anteriores, con los atentados terroristas del 11 de septiembre de 2001 como un punto de inflexión más en el ámbito regional que en el universal.

Particular interés, por supuesto, tiene la evolución normativa del contenido y el alcance de la obligación principal. La extradición rivalizaba con el asilo (artículo 12 de la Convención de Nueva York de 1973 y artículo 15 de la Convención de Nueva York de 1979) y, desde luego, la extradición y la asistencia judicial recíproca en materia penal se encontraban con la excepción del delito político ${ }^{40}$. Los primeros tratados 
aludían simplemente a la obligación de los Estados de adoptar la decisión relativa a la extradición o, en su defecto, al enjuiciamiento «en las mismas condiciones que las aplicables a los delitos comunes de carácter grave, de acuerdo con la legislación de tal Estado», así como a la obligación de prestarse la mayor ayuda posible por lo que respecta a todo proceso penal, de conformidad con la legislación del Estado requerido ${ }^{41}$. Incluso el Convenio Europeo para la Represión del Terrorismo, de 1977, permitió en su artículo 13 que un Estado parte declarara que, bajo algunas condiciones, se reserva el derecho de denegar la extradición con base en la excepción del delito político - lo que, por cierto, aunque con más condiciones, sigue permitiendo tras el Protocolo de Enmienda de 2003-.

Los convenios de Nueva York de 1997, 1999 y 2005, por el contrario, incluyen una disposición conforme con la cual:

[...] a los fines de la extradición o de la asistencia judicial recíproca ninguno de los delitos enunciados [en esos Convenios] se considerará delito político, delito conexo a un delito político ni delito inspirado en motivos políticos. En consecuencia, no podrá rechazarse una solicitud de extradición o de asistencia judicial recíproca formulada en relación con un delito de ese carácter por la única razón de que se refiere a un delito político, un delito conexo a un delito político o un delito inspirado en motivos políticos ${ }^{42}$.

Lo que no ha sido suprimido - por el contrario, se amplía a nuevos motivos humanitarios, como hace el Protocolo de Enmienda de 2003 al Convenio Europeo para la Represión del Terrorismo- es la posibilidad de denegar la extradición o la asistencia judicial recíproca en materia penal con base en la "cláusula humanitaria», en virtud de la que:

[...] nada de lo dispuesto en el [Convenio] se interpretará en el sentido de que imponga una obligación de extraditar o de prestar asistencia judicial recíproca si el Estado al que se presenta la solicitud tiene motivos fundados para creer que la solicitud de extradición por los delitos enunciados [en el Convenio] o de asistencia judicial recíproca en relación con esos delitos se ha formulado con el fin de enjuiciar o castigar a una persona por motivos de raza, religión, nacionalidad, origen étnico u opinión política, o que el cumplimiento de lo solicitado podría perjudicar la situación de esa persona por cualquiera de esos motivos ${ }^{43}$.

De no proceder a la extradición de un presunto terrorista, el Estado parte en cuyo territorio se encuentre el presunto terrorista está obligado a enjuiciarlo. En realidad, ese Estado está obligado: 
[...] a someter sin demora indebida el caso a sus autoridades competentes a efectos de enjuiciamiento, según el procedimiento previsto en la legislación de ese Estado, sin excepción alguna y con independencia de que el delito haya sido o no cometido en su territorio. Dichas autoridades tomarán su decisión en las mismas condiciones que las aplicables a cualquier otro delito de naturaleza grave de acuerdo con el derecho de tal Estado ${ }^{44}$.

No es solo la independencia del poder judicial lo que explica esa redacción. También habría que dar cabida tanto a los Estados que se rigen por el principio de legalidad como a los que se rigen por, o de otro modo contemplan en su Derecho interno, el principio de oportunidad de las actuaciones judiciales.

Por otra parte, para proceder a la extradición o para someter el caso a las autoridades competentes a efectos de enjuiciamiento, previamente habría que procederse a la detención o a la toma de otras medidas a fin de asegurar la presencia de la persona a tales efectos. Pues bien, los tratados internacionales no solo reconocen que habrán de tomarse las medidas que correspondan conforme con la legislación nacional del Estado en cuyo territorio se encuentre el terrorista o presunto terrorista, sino que dicho Estado tomará medidas «si estima que las circunstancias lo justifican» ${ }^{45}$, sin precisarse de otro modo cuáles pueden ser las circunstancias que justificarían no tomar medidas. Puede entenderse fácilmente que la Convención de Nueva York de 1979 se interprete en el sentido de incluir entre esas circunstancias la situación de los rehenes: de hecho, el párrafo primero del artículo 3 estipula que «[...] el Estado parte en cuyo territorio el delincuente tenga detenido al rehén adoptará todas las medidas que considere apropiadas para aliviar la situación del mismo, en particular para asegurar su liberación, y, una vez que haya sido liberado, para facilitar, cuando proceda, su salida del país».

¿Es posible no detener o no enjuiciar, o liberar, a terroristas o presuntos terroristas... más allá de como resultado de una negociación por la circunstancia humanitaria de aliviar la situación de un rehén, en particular para asegurar la liberación del rehén?

\section{LAS OBLIGACIONES DE ORIGEN O NATURALEZA NO CONVENCIONAL EN SENTIDO ESTRICTO RELATIVAS A LA LUCHA CONTRA EL TERRORISMO}

El DI tradicional contenía ya ciertos principios - inspirados en los deberes vinculados a la idea de soberanía territorial, que fueran tan claramente enunciados por el árbitro Max Huber en la sentencia del 4 de abril de 1928, en el asunto de la «Isla de Palmas», y en el deber 
de neutralidad — que, por analogía, pueden considerarse hoy parte del marco jurídico para la lucha contra el terrorismo: el principio relativo a la prevención de los daños ocasionados a extranjeros en el territorio nacional y el principio de prevención de daños causados por bandas armadas que actúan en territorio extranjero a partir del territorio nacional.

En realidad, tras el magnicidio de Marsella, en 1934, el Consejo de la Sociedad de Naciones no hizo más que considerar y adaptar las normas aplicadas en 1872 por el Tribunal Arbitral del asunto del «Alabama», esto es, las llamadas «Reglas de Washington». La práctica de los Estados y la doctrina de la época corroboraban la existencia de una obligación de prevención de los actos y actividades terroristas al margen de un vínculo convencional ${ }^{46}$. Posteriormente, como dije, la resolución 2625 (XXV) de la Asamblea General de las Naciones Unidas y otras muchas resoluciones de la Asamblea General sobre medidas para eliminar el terrorismo internacional, incluida la declaración anexa a las resoluciones 49/60 y 51/210, y del Consejo de Seguridad sobre determinados actos terroristas o sobre los actos terroristas en general como amenazas a la paz y la seguridad internacionales, confirmaron que esa obligación general no encuentra discusión ${ }^{47}$.

En definitiva, es innegable que todos los Estados tienen la obligación de prevenir el terrorismo, y desde luego de no cometer actos terroristas, y el origen de esa obligación no solo es convencional —y en el ámbito de los tratados en cuestión - sino que también tiene su origen en la costumbre internacional o en los principios generales del Derecho reconocidos por las naciones civilizadas o en los principios generales del DI, así como en decisiones del Consejo de Seguridad de las Naciones Unidas, particularmente a partir de la contenida en la resolución 1373 (2001) del 28 de septiembre de 2001.

¿Y la obligación de reprimir el terrorismo? Tradicionalmente, el DI ha reconocido a los Estados derechos y obligaciones con una base esencialmente territorial y, en menor medida, personal —el ejercicio extraterritorial de la jurisdicción de los Estados era y sigue siendo discutido-, y, por ello, cualquier Estado tiene desde luego derecho a juzgar a las personas que cometen actos terroristas en su territorio y, en menor medida, cuando esas personas son sus nacionales o atentan contra sus nacionales en territorio extranjero. Por esto también, tradicionalmente, solo el Estado en cuyo territorio se cometía un acto terrorista contra otro Estado estaba obligado a extraditar o juzgar a los terroristas o presuntos terroristas, independientemente de que hubiera observado o no la diligencia debida en la prevención de tal acto terrorista.

¿ES POSIBLE ATRIBUIR RESPONSABILIDAD INTERNACIONAL A LOS ESTADOS ACUSADOS DE COMETER ACTOS TERRORISTAS? 
Como ningún Estado distinto del soberano territorial tenía, de acuerdo con el DI general, la obligación de extraditar o juzgar a los terroristas o presuntos terroristas, todos los otros Estados tenían tradicionalmente otra opción: no hacer ni lo uno ni lo otro; no hacer nada y, por lo tanto, facilitar la impunidad de los terroristas. La elaboración y la adopción de las convenciones de Ginebra de 1937 pretendía colmar esa laguna del DI y, después de 1945, muchos tratados, tanto en el ámbito del DI humanitario cuanto en el de la lucha contra el terrorismo propiamente dicha, han incorporado la obligación de extraditar o juzgar. Deducir de la práctica de los Estados y de la opinio juris la vigencia actual de esa obligación en el DI general no es fácil. No obstante, el desequilibrio que pudiera percibirse en la primera mitad del siglo XX entre la obligación de prevenir y la obligación de reprimir el terrorismo pudiera haberse corregido por el interés que la lucha contra el terrorismo suscita hoy día para la comunidad internacional. De ahí que, tal vez, podría afirmarse no solo el derecho sino también la obligación general de todos los Estados de extraditar o juzgar a los terroristas o presuntos terroristas que se encuentran en su territorio -identificados como tales terroristas, al menos, por la comisión de uno de los delitos comprendidos en los tratados universales-, sean de la nacionalidad que sean y dondequiera que sea que hayan cometido los actos terroristas.

Si bien existen distintas interpretaciones sobre el sentido de la interacción entre los tratados, por ejemplo los antiterroristas y el DI general, esos tratados relativos a la lucha contra el terrorismo internacional representarían una buena manifestación de que la jurisdicción extraterritorial está en franca expansión. Sería difícil sostener que lo que es expresamente obligatorio, e incluso lo que está simplemente permitido en virtud de un tratado universal para la lucha contra el terrorismo internacional, no está permitido por el DI general, es decir, con independencia de que los Estados sean partes o no en dichos tratados.

Por otra parte, la Asamblea General y el Consejo de Seguridad de las Naciones Unidas han declarado en numerosas ocasiones que los Estados deben asegurarse de aprehender y extraditar o enjuiciar a los terroristas. Asimismo, deben asegurarse de no reconocer asilo o el estatuto de refugiado a terroristas y que este estatuto no se utilice para la comisión de actos terroristas, así como que aquellos que buscan asilo y están a la espera de la tramitación de sus solicitudes no pueden de ese modo eludir su persecución por actos terroristas ${ }^{48}$. Y, no obstante, la doctrina no auxilia en la determinación de la existencia de esa obligación general ${ }^{49}$.

48 Porejemplo,enlaDeclaración de1994sobreMedidasparaEliminarelTerrorismolnternacional(resolución 49/60) y en la Declaración Suplementaria de 1996 (resolución 51/210), de la Asamblea General, o en la resolución 1269 (1999), del 19 de octubre de 1999, del Consejo de Seguridad.

49 Porejemplo, noexistetalobligación general para CARRILLOSALCEDO,J.A. «Les aspects juridiques....». Op. cit., pp. 23 y 39-45; ni para y Frowein. «The Legal Aspects...». Op. cit., pp. 78-85; sí para JimÉnEZ de ArÉchaGA, E. «International Law in the Past Third of a Century. General Course in Public International Law». RCADI, vol. 159, 1978/I, pp. 1-344, p. 64. La misma dualidad de criterios se reprodujo entre los jueces de la ClJ que suscribierondeclaracionesuopinionesseparadasenrelaciónconlasprovidenciasdelaCorteenlosasuntos sobre «Cuestiones de interpretación y aplicación de la Convención de Montreal de 1971 surgidas a raíz del 
De cualquier forma, dos últimos rasgos deben subrayarse de esas obligaciones de origen o naturaleza no convencional relativas a la lucha contra el terrorismo: por un lado, aquí no es tan precisa la distinción entre actos de terrorismo «internacional» y otras manifestaciones del terrorismo «nacional»o «interno» (aunque, en apariencia, las resoluciones de la Asamblea General persigan la eliminación del terrorismo internacional, normalmente el texto de las resoluciones de la Asamblea y las recomendaciones y decisiones del Consejo de Seguridad confieren trascendencia internacional a cualquier acto terrorista); por otro, esas obligaciones tampoco se vertebran en torno a una definición más precisa del terrorismo (aunque en las resoluciones de la Asamblea General se perfilan elementos de esa definición, como el propósito terrorista, que después se han incorporado en tratados e, incluso, en decisiones del Consejo de Seguridad ${ }^{50}$ ).

\section{IV.RECAPITULACIÓN: LA EXISTENCIA DE UNA VIOLACIÓN DE UNA OBLIGACIÓN INTERNACIONAL... Y LA ATRIBUCIÓN DE LOS ACTOS TERRORISTAS AL ESTADO}

Establecida la existencia de obligaciones internacionales que vinculan a un Estado para la prevención y, en su caso, represión de los actos terroristas - y, muy preliminarmente, el contenido y alcance de esas obligaciones-, determinar la responsabilidad internacional de dicho Estado exige atribuir al Estado, según el DI, el comportamiento constitutivo de una violación de una de esas obligaciones, esto es, del comportamiento que no es conforme con lo que del Estado exige la obligación.

En principio, no es necesario, por tanto, indagar sobre el daño o sobre la culpa - posiblemente porque sean inherentes a la ilicitud-, ni sobre el abuso de derecho; pero la implicación de un Estado en actos y actividades terroristas, y más precisamente la atribución directa e inmediata de actos terroristas a un Estado, no parece posible, desde luego, con una simple culpa — culpa in vigilando, negligencia culpable o falta de la diligencia debida-, sin que exista una intención dolosa, lo

incidenteaéreoen Lockerbie": : paralosjuecesEvensen, Tarassov, Guillaumey AguilarMawdsley,noexistía enelDIgeneraltalobligación,mientrasqueotrosjuecesafirmabandichaexistencia(Badjaoui, Weeramantry, Ranjeva oEI-Kosheri). En su 57º período de sesiones(2005), la CDI decidió incluir el tema «La obligación de extraditar o juzgar (aut dedere aut judicare)" en su programa de trabajo y nombró relator especial del tema al señor Zdzislaw Galicki. Hasta ahora, la Comisión ha recibido y examinado el informe preliminar (2006) y el segundo(2007) y tercer informes(2008)del relatorespecial, asícomola información y las observaciones recibidasdelosgobiernos, justamenteconlapretensióndedeterminarsilaobligacióndeextraditarojuzgar existe en el ámbito deI DI consuetudinario o como principio general del Derecho. La Comisión ha decidido establecerungrupodetrabajosobreeltema, presididoporelseñor Alain Pellet,cuyomandatoycomposición se determinarán en el siguiente período de sesiones.

50 Por ejemplo, cuando, en el párrafo 3 dispositivo de su resolución 1566 (2004), del 8 de octubre de 2004, el ConsejodeSeguridadrecuerdaque «losactoscriminales, inclusivecontraciviles,cometidosconlaintención decausarlamuerteolesiones corporales gravesodetomarrehenesconel propósitodeprovocarunestado de terror en la población en general, en un grupo de personas o en determinada persona, intimidar a una población u obligar a un gobierno o a una organización internacional a realizar un acto, o a abstenerse de realizarlo,queconstituyendelitosdefinidosenlosconvenios,lasconvencionesylosprotocolosinternacionales relativos al terrorismo y comprendidos en suámbito, no admiten justificación en circunstancia alguna por consideraciones deíndolepolítica,filosófica, ideológica, racial,étnica, religiosau otrasimilare instaatodos losEstadosaprevenirlosy,siocurren, acerciorarsedequeseansancionadosconpenascompatiblesconsu grave naturaleza». 
que repercutiría, además, en el contenido de la responsabilidad. Pero, en cualquier caso, la culpa o el dolo son necesarios en principio para determinar las condiciones de la violación de la obligación de prevenir - y reprimir - el terrorismo, influidas por el criterio de la diligencia debida, y no para la atribución al Estado del hecho ilícito resultante. La persistencia de una violación, podría, no obstante, influir también en la atribución del hecho al Estado.

\section{La atribución de un comportamiento (eventualmente de actos terroristas) al Estado}

Esta operación no siempre es fácil, como se puso de manifiesto, por ejemplo, con el debate en torno a la eventual atribución a Afganistán de los ataques terroristas del 11 de septiembre de 2001, al parecer cometidos por Al-Qaida, protegida por la facción talibán en Afganistán, entonces gobierno de facto (aunque esa atribución no fuera imprescindible para quienes mantienen que la legítima defensa puede ejercerse no solo frente a un ataque armado de un Estado, sino también frente a un ataque armado desde un Estado).

Según el DI, como principio -inspirado en los principios de autoorganización y buena fe-, se atribuye al Estado el comportamiento, la acción o la omisión de cualquiera de sus órganos de jure - conforme con el Derecho interno- o de facto - por su «completa dependencia» del Estado-, sea que ejerza funciones legislativas, ejecutivas, judiciales o de otra índole, cualquiera que sea su posición en la organización del Estado, y tanto si pertenece al gobierno central como a una división territorial del Estado ${ }^{51}$. Ocurre lo mismo cuando se trata de personas o grupos de personas o entidades y de órganos puestos a disposición de un Estado por otro Estado, que ejercen atribuciones del poder público ${ }^{52}$, independientemente de si el comportamiento se lleva a cabo en su territorio o en el territorio de otro Estado e, incluso, de si el órgano se extralimita en su competencia o contraviene instrucciones ${ }^{53}$.

También son hechos de un Estado los actos terroristas cometidos por un movimiento insurreccional que se convierta en el nuevo gobierno del Estado o del nuevo Estado, así como los actos terroristas de un movimiento insurreccional o de otra índole que logre establecer ese nuevo Estado en parte del territorio de un Estado preexistente o en un territorio sujeto a su administración ${ }^{54}$.

No obstante, no todo comportamiento de un órgano es atribuible al Estado, y no solo y exclusivamente el comportamiento de sus órganos puede atribuirse al Estado. 
Excepto en el ámbito de aplicación del DI humanitario - por lo que hace al comportamiento de las personas que forman parte de las fuerzas armadas- - para que el comportamiento de un órgano del Estado pueda ser atribuido al Estado, la persona debe haber actuado en calidad de órgano del Estado. Eso sí: salvo prueba en contrario, debe presumirse que los órganos de los Estados actúan en esa calidad.

Y también se atribuirá a un Estado el comportamiento de cualquier persona o grupo de personas que actúa de hecho por instrucciones o bajo la dirección o el control de ese Estado al observar dicho comportamiento ${ }^{55}$, esto es, que actúan como «agentes» del Estado. Es bien conocida, en este sentido, la discrepancia de criterio sobre la «intensidad» del control de la CIJ («control efectivo de cada una de las operaciones militares o paramilitares en el transcurso de las cuales se cometieron las presuntas violaciones») $)^{56}$ y el TPIY («control general de las operaciones») ${ }^{57}$, en vista de que la CIJ reafirma su competencia para decidir, contrariamente al TPIY, sobre la responsabilidad de los Estados. En cualquier caso, la presunción tiene aquí efecto en el sentido de, salvo prueba en contrario, por rigurosa que sea la prueba, no considerar hecho del Estado el comportamiento de personas, de grupos o de entidades que no son sus órganos.

Por último, si, en ocasión de la comisión de actos terroristas por personas o grupos de personas que, en principio, no actúan de hecho por instrucciones o bajo la dirección o el control de ese Estado, el Estado territorial viola persistentemente sus obligaciones relativas a la prevención o represión del terrorismo, pueden verse atribuidos como propios tales actos terroristas. Como dijera la CIJ en su sentencia del 24 de mayo de 1980, si el Estado territorial es plenamente consciente de sus obligaciones y de la necesidad urgente de adoptar medidas apropiadas, y cuenta con los medios a su disposición para cumplir sus obligaciones y deja por completo de cumplirlas, los actos terroristas cometidos por personas o grupos de personas que en principio no actuaban de hecho por instrucciones o bajo la dirección o el control de ese Estado terminan atribuyéndose al Estado mismo y le hacen incurrir en responsabilidad internacional ${ }^{58}$. La CDI ha incluido, en su proyecto de artículos, una disposición relativa a la atribución al Estado de un hecho en el caso y en la medida en que el Estado reconozca y adopte ese comportamiento como propio ${ }^{59}$.

En conclusión, pueden atribuirse a un Estado actos terroristas cuando, de un lado, se prueba que los terroristas son órganos, de jure o de facto, del Estado y este no desvirtúa la presunción de que han actuado en

55 Artículo 8 del proyecto de artículos de la CDI.

56 En particular, en las sentencias del27 dejunio de 1986(asunto de las «Actividades militares y paramilitares en y contra Nicaragua" [Nicaragua c. Estados Unidos de América]. ICJ Reports 1986, p. 65) y del 27 de febrero de 2007 (asunto de la «Aplicación de la Convención sobre la prevención y sanción del crimen de genocidio" [Bosnia y Herzegovina c. Serbia y Montenegro]. ICJ Reports 2007, p. 65).

57 Caso Tadić, sentencia de la Sala de Apelaciones del TIPY del 15 de julio de 1999 (IT-94-1-A, Judgment, 15 July 1999).

58 Asuntodel «PersonaldiplomáticoyconsulardelosEstadosUnidosenTeherán»(EstadosUnidosdeAmérica c. Irán). ICJ Reports 1980, p. 32-33 y 35.

59 Artículo 11 del proyecto de artículos de la CDI. 
esa calidad y, de otro, cuando se prueba que los terroristas actúan de hecho por instrucciones o bajo la dirección o el control de ese Estado, o cuando, de otro modo, el Estado reconoce y adopta esos actos terroristas como propios al violar persistentemente sus obligaciones relativas a su prevención y represión.

\section{La constatación de la violación de las obligaciones relativas a la prevención y represión del terrorismo}

Ante la comisión de actos terroristas por un Estado, podríamos estar ante una alteración del carácter absoluto de la correlación entre incumplimiento de una norma de Derecho, violación de una obligación y lesión de un derecho. Sucede que las violaciones graves de obligaciones emanadas de normas imperativas de DI general generan obligaciones para todos los Estados; además, los que la CDI ha denominado finalmente «Estados distintos del Estado lesionado» pueden invocar la responsabilidad del Estado si la obligación violada protege un interés colectivo o, como en el caso de las obligaciones relativas a la prevención y represión del terrorismo, si existe con relación a la comunidad internacional en su conjunto $^{60}$. De este modo, las obligaciones relativas a la prevención y la represión del terrorismo combinan el resultado a alcanzar, y las modalidades de su ejecución y exigen, por parte de los Estados, observar una diligencia debida. En último extremo, la comisión de actos terroristas y la falta de sanción a los terroristas no significan necesariamente que un Estado, incluido el Estado en cuyo territorio ha tenido lugar el acto terrorista o en el que se encuentra el terrorista, haya violado sus obligaciones internacionales.

El jurista debe examinar no solo qué se exige a los Estados, sino que, para determinar cuándo y en qué condiciones existe la violación de una obligación, también ha de preguntarse en cada caso concreto cómo se exige del Estado el cumplimiento de sus obligaciones, lo que determinará los hechos sobre los que habrá de recaer la prueba de quien pretenda la existencia de esa violación.

\subsection{El dolo y el criterio de la «diligencia debida»}

La obligación del Estado territorial es relativa porque un Estado no puede ser responsable de todo lo que ocurra en su territorio: el enunciado del criterio de la diligencia debida por el árbitro Huber, en el laudo del primero de mayo de 1925 sobre el asunto de las «Propiedades británicas en el Marruecos español», puede considerarse una piedra de toque lógica para definir la obligación de prevenir incidentes tales como actos terroristas, pues, sin probarse la existencia de negligencia del Estado en cuyo territorio se cometen los actos terroristas en otro Estado, no puede determinarse la violación de la obligación de prevención. 
Un Estado debe prevenir los daños que puedan ocasionarse a extranjeros en su territorio, en particular si ha sido advertido del peligro, al seguir una diligentia quam in suis y, por tanto, generalmente solo está obligado a asegurar una protección igual a los extranjeros que a los nacionales; en el mejor de los casos, tiene un deber de vigilancia especial, en particular cuando así se reconoce expresamente en DI — por ejemplo, los agentes diplomáticos o consulares- o se puede deducir por las circunstancias en las que se halla en el territorio del Estado. En este sentido, la respuesta del Comité Especial de Juristas en relación con el caso del «Asesinato de los miembros italianos de la misión Tellini» (o «Incidente de Janina», 1923) y, años después, la sentencia de la CIJ en el asunto del «Personal diplomático y consular de EEUU en Teherán». Una sucesión de actos terroristas en el territorio de un Estado contra otro Estado o sus nacionales puede exigir igualmente una especial diligencia en la prevención de estos.

La diligencia exigible a un Estado para la prevención y la represión de actos terroristas en su territorio debe examinarse según cada caso, ya que depende de las circunstancias presentes, en particular de la efectividad de la autoridad del Estado y, por lo tanto, de los medios y la información a su disposición. La presunción de efectividad del Estado territorial no implica conocimiento necesario de los actos contrarios al DI que puedan cometerse en el territorio de dicho Estado, pero, al mismo tiempo, esa presunción «desempeña una función de extraordinaria importancia respecto de los medios de prueba y en relación con el fundamento de la responsabilidad internacional del Estado» ${ }^{61}$.

$\mathrm{Al}$ ser en buena parte abstracto e indeterminado, el criterio de la diligencia debida adquiere precisión tanto en la práctica de los Estados cuanto en la jurisprudencia y la doctrina. En este sentido, en su sentencia del 11 de septiembre de 1949, la Corte rechazó tanto la tesis del conocimiento necesario por el soberano territorial de los actos contrarios al DI cuanto la tesis de una responsabilidad objetiva del soberano territorial; sin embargo, sobre la base de la existencia de obligaciones que incumben al soberano territorial y de la presunción de su control efectivo, la Corte admitió que debía permitirse al Estado que alega la responsabilidad del Estado territorial «recurrir más ampliamente a las presunciones de hecho, a los indicios o pruebas circunstanciales ('circumstantial evidence') $\gg^{62}$. Esto no implica la inversión de la carga de la prueba o la determinación automática de la existencia de responsabilidad del Estado territorial, pues el éxito de la alegación de que un acto terrorista se organizó en el territorio y con la complicidad o por la negligencia de un Estado, más aún que el acto terrorista ha sido cometido por el Estado, exige una actividad probatoria. 
Debe tenerse en cuenta que la imprevisibilidad y clandestinidad con que se organizan y cometen los actos terroristas hacen difícil la obtención previa de información. Diversas circunstancias pueden ayudar a evaluar la diligencia o negligencia del soberano territorial en el cumplimiento de su obligación: por ejemplo, el conocimiento de que el territorio se está utilizando como base para cometer actos terroristas, bien por las quejas de otro Estado o por la notoriedad de las actividades terroristas; no ejercer la debida diligencia en el control de las actividades una vez conocidas - entre otras medidas, detener y extraditar o enjuiciar a las personas implicadas en los actos terroristas; la tolerancia o aquiescencia en la utilización de su territorio; los daños sufridos por personas en otro Estado, etcétera.

Cuandose pretendeque unEstadono solose comportanegligentemente, sino que incumple dolosamente sus obligaciones, las pruebas no deben dejar lugar a dudas.

\subsection{La violación de las obligaciones relativas a la prevención del terrorismo}

La violación de las obligaciones relativas a la prevención de actos terroristas solo podría determinarse si el acto terrorista es atribuible al Estado o si ha tenido lugar como consecuencia de la ausencia o de la deficiencia del sistema de prevención que el Estado estaba obligado a establecer. En este último supuesto, es necesario, además, que concurran dos condiciones: (a) que el acto terrorista se haya cometido; y (b) que se haya cometido precisamente como consecuencia de la deficiente prevención por parte del Estado.

El DI impone también otras obligaciones que exigen un comportamiento específicamente determinado, a través del cual todo Estado ha de asegurar el cumplimiento de esa obligación de prevención. En la formulación de estas obligaciones, el grado de determinación del comportamiento de los Estados peca, aunque sea por reiterativo, de excesiva imprecisión. No obstante, podrá determinarse la existencia de una violación de dichas obligaciones en el momento en que, por un lado, un Estado organiza, instiga, ayuda, fomenta, apoya, financia o participa en esos actos terroristas, o, por otro, tolera en su territorio la organización de actividades encaminadas a la comisión de tales actos. El cumplimiento de estas obligaciones exige, a su vez, adoptar las medidas apropiadas para, dentro de lo posible, conocer la existencia dentro de su territorio de personas o grupos empeñados en la comisión de tales actos y, una vez conocida la existencia de esas personas o grupos, proceder a su prohibición y disolución. Igualmente, podrá determinarse la violación por un Estado de sus obligaciones internacionales en el preciso momento en que no transmite a los Estados interesados con la celeridad necesaria, o simplemente no transmite, la información que obra en su poder referente a la comisión de actos terroristas contra esos Estados. 
Es importante señalar que esas obligaciones pueden violarse con independencia de que se cometan o no los actos terroristas, en particular cuando un Estado consiente la organización de actividades encaminadas a su comisión dentro de su territorio; es decir, no siempre es necesaria la comisión del acto terrorista para determinar que un Estado viola sus obligaciones relativas a la prevención de los actos terroristas. En tales situaciones, no influiría, por tanto, el hecho de que la ilicitud resultante del contraste entre el comportamiento adoptado y el que debería haber adoptado de acuerdo con el DI haya engendrado o no daños personales o materiales a otro Estado.

Cuando un acto terrorista no pueda atribuirse a un Estado, puede que ese Estado todavía haya violado, en relación con dicho acto terrorista, sus obligaciones internacionales relativas a la prevención del terrorismo, tanto si el acto terrorista se cometió en su territorio como si lo fue en el territorio de otro Estado; en este caso, el acto terrorista constituiría un acontecimiento exterior que opera como «catalizador» de la ilicitud del comportamiento del Estado que ha incumplido, en ocasión del acto terrorista, su obligación de establecer un razonable sistema de vigilancia, protección y control.

Por lo demás, las realidades de la vida internacional exigen que las obligaciones relativas a la prevención del terrorismo desplieguen su eficacia en aquellas situaciones en las que, aun cuando el Estado territorial no esté en principio implicado en tales actos y actividades y, en este sentido, observe la debida diligencia, acaezca en su territorio un acto terrorista contra otro Estado o sus nacionales: tal es el caso, por ejemplo, de los apoderamientos ilícitos de naves o aeronaves que son desviadas hacia el territorio sometido a la jurisdicción de ese Estado. El deber de diligencia exige del Estado territorial la adopción de todas las medidas apropiadas para la rápida terminación del acto terrorista, teniendo en cuenta el difícil equilibrio entre limitar los riesgos para la vida o la integridad física de las víctimas y garantizar su seguridad y procurar la liberación de los rehenes, de un lado, y, de otro, detener y extraditar o juzgar a los terroristas.

\subsection{La violación de las obligaciones relativas a la represión del terrorismo}

Tras detener o asegurar la presencia de los terroristas o presuntos terroristas, un Estado solo viola sus obligaciones internacionales si no extradita y no somete el asunto a sus autoridades competentes a efectos del ejercicio de la acción penal, sin determinarse específicamente el resultado del ejercicio de la acción penal.

Los Estados, no obstante, violarían sus obligaciones internacionales si no se comportan del modo específicamente determinado accesoriamente a dicha obligación principal: si no adoptan las medidas necesarias para que su legislación interna considere como delitos los actos terroristas previstos en el DI y no establecen en determinados supuestos su

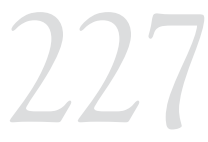

¿ES POSIBLE

ATRIBUIR RES-

PONSABILIDAD

INTERNACIONAL

A LOS ESTADOS

ACUSADOS DE

COMETER ACTOS

TERRORISTAS? 
jurisdicción respecto de tales actos terroristas; si no detienen o adoptan otras medidas para asegurar la presencia del terrorista o presunto terrorista a los fines de su extradición o enjuiciamiento ${ }^{63}$; si no proceden inmediatamente a una investigación preliminar sobre los hechos; si no prestan asistencia judicial en materia penal; y, en su caso, si no suministran a los Estados y organizaciones internacionales interesadas cualquier información relativa a las circunstancias de los actos y actividades terroristas, a la detención, la investigación preliminar sobre los hechos y a la extradición o enjuiciamiento.

\subsubsection{En relación con la extradición}

Únicamente podremos concluir la existencia de una violación de sus obligaciones en el supuesto de aquellos Estados parte en los respectivos tratados internacionales que:

1. no consideren los actos terroristas contemplados entre los delitos que dan lugar a extradición en todo tratado de extradición celebrado con anterioridad a la entrada en vigor para cada Estado del tratado en cuestión, entre Estados parte, o bien no hayan incluido el delito como caso de extradición en un tratado de extradición celebrado con posterioridad a la entrada en vigor para cada Estado del tratado en cuestión;

2. sin subordinar la extradición a la existencia de un tratado, no reconozcan el acto terrorista como caso de extradición; y

3. a efectos de la extradición, dejen de considerar como lugar de la comisión del acto terrorista no solo donde ocurrió sino también el territorio de los Estados obligados a establecer su jurisdicción —o el territorio del Estado requirente de la extradición-.

Salvo entre los Estados parte de los convenios de Nueva York de 1997, 1999 y 2005, no existe violación de obligaciones cuando un Estado deniega la extradición de un presunto terrorista porque considera su delito como un delito político, conexo con un delito político o inspirado por móviles políticos.

\subsubsection{En relación con el ejercicio de la acción penal y el cumplimiento de las condenas}

Si elDI respeta, a efectos del ejercicio de la acción penal, las peculiaridades procesales de los Estados, el cumplimiento de buena fe de la obligación internacional de reprimir el terrorismo, y por tanto impedir la impunidad de los terroristas ${ }^{64}$, significa que, en caso de existir indicios razonables de

63 LaineficaciaolaincapacidaddelEstadoparaprocederadichadetenciónnosonensímismassuficientespara concluirqueelEstadoviolasusobligacionesinternacionales,porqueúnicamenteseexigequeadoptedebuena fe las medidas razonablemente necesarias.

64 Incluso de aquellos que, para llevar a cabo actos terroristas, abusan de los privilegios e inmunidades diplomáticos. En virtud de la Convención de Viena de 1961, el Estado receptor ha de respetar la inmunidad jurisdiccionaldelosagentesdiplomáticos(artículo31.1);noobstante,auncuandoestaexcepciónfueraválida 
criminalidad, debe procesarse y enjuiciarse al presunto terrorista y, una vez probada su culpabilidad $-\mathrm{y}$ vistas las circunstancias que pudieran atenuar la responsabilidad penal-, debe imponerse una condena conforme con la gravedad del acto terrorista.

Convencionalmente, los Estados se obligan a establecer penas severas o adecuadas que tengan en cuenta el carácter grave de los actos y a que sus autoridades tomen las decisiones en las mismas condiciones que las aplicables a los delitos comunes de carácter grave. El análisis de la práctica arbitral, en particular de algunos de los asuntos examinados por la Comisión General de Reclamaciones entre Estados Unidos y México (asuntos «Galván» o «Chase»), indica que, para cumplir la obligación general, no es suficiente el simple procesamiento. La falta de pruebas a disposición de las autoridades o su carácter poco concluyente pueden, no obstante, precluir el enjuiciamiento o la condena de una persona, sin poder entonces determinarse la existencia de violación de obligaciones. Asimismo, la obligación de imponer una pena adecuada es parte del DI general, pero la práctica internacional no es concluyente al considerar un estándar de la pena adecuada que ha de ser efectivamente cumplida, y en la práctica de los Estados pueden encontrarse ejemplos extremos, tanto de severidad cuanto de indulgencia.

En este orden de ideas, el DI contempla la violación de obligaciones de los Estados por actos u omisiones de sus órganos judiciales contrarios al Derecho, cuando no han actuado con indudable buena fe o cuando los jueces evidentemente se han dejado influir por consideraciones ajenas a la administración de justicia. En efecto, los Estados violan sus obligaciones internacionales tanto por la denegación de justicia cuanto por dictar sentencias que sean manifiestamente injustas — siguiendo la distinción entre déni de justice y défi de justice-, si bien existe una tendencia a ampliar el concepto tradicional de la denegación de justicia para incluir dentro de dicha expresión otros actos del poder judicial, tales como los fallos manifiestamente injustos o parciales. No obstante, de acuerdo con la regla del agotamiento previo de los recursos internos, no podría exigirse responsabilidad al Estado por esa violación hasta el momento en que la decisión de las autoridades competentes, contraria a las obligaciones internacionales del Estado, sea definitiva.

Por otra parte, en la determinación de la violación por un Estado de sus obligaciones, deben tomarse en cuenta, por último, dos situaciones excepcionales. En primer lugar, los supuestos a los que me he referido anteriormente en que los Estados negocian con los terroristas para lograr la liberación de rehenes. Una vez que la situación de urgencia humanitaria no existe, se restablecen las obligaciones. En segundo lugar,

¿ES POSIBLE ATRIBUIR RESPONSABILIDAD INTERNACIONAL A LOS ESTADOS ACUSADOS DE COMETER ACTOS TERRORISTAS? 
¿incumpliría sus obligaciones internacionales un Estado que, al haber impuesto una condena, conceda una amnistía o el indulto a los condenados por actos terroristas? En un contexto distinto al del terrorismo, aunque análogo en su problemática relativa al delito político (insurrecciones y guerras civiles), se ha escrito que:

[...] los indultos y las concesiones de amnistía en general han ocasionado la responsabilidad del Estado por daños, en virtud del fundamento de haber dejado de sancionar efectivamente. Aunque esto es cierto en el caso de delincuentes comunes, la regla no se puede extender, sin salvedades, a los insurgentes. Si la amnistía es de carácter general, fundada en razones de política nacional y concedida con el propósito de lograr la pacificación de un país, no entraña responsabilidad para el Estado, puesto que se aplica a delitos políticos o relacionados con la política [...]. La respuesta debe ser distinta en el caso de delitos comunes, que no se pueden considerar como incidentes normales de una guerra civil ${ }^{65}$.

¿Un Estado que conceda una amnistía o el indulto a los condenados por actos terroristas incumple su obligación de que sus autoridades competentes adopten sus decisiones en las mismas condiciones que las aplicables a los delitos comunes de carácter grave?

La práctica arbitral muestra que solo excepcionalmente una amnistía no viola las obligaciones del Estado, al considerarse no como un acto de indulgencia sino más bien como un esfuerzo supremo por alcanzar la pacificación del país. Si la pacificación de un determinado territorio requiriese adoptar este tipo de medidas - políticas pero con consecuencias jurídicas-, el DI encuentra el problema político que generalmente subyace al terrorismo. En este sentido, la práctica de los Estados durante los procesos de descolonización se mostró flexible, como lo hizo en decisiones tomadas en procesos de democratización — por ejemplo, la República de Sudáfrica — o de pacificación — por ejemplo, Oriente Medio- . No obstante, los actos terroristas no pueden calificarse como «incidentes normales», incluso de una guerra de liberación nacional, y considero que debe primar su calificación como delitos comunes de carácter grave. La licitud de la concesión de una amnistía o indulto estaría, por tanto, en función de la gravedad de los actos violentos y de que se ocasionaran o no daños a otros Estados o sus nacionales ${ }^{66}$. Pero, sin dudas, lo que en caso alguno sería admisible, particularmente ante la comisión por el Estado de actos terroristas, es una «autoamnistía».

65 JimÉnEZdeArÉCHAGA,E. «Responsabilidadinternacional».EnM.Sørensen(editor). ManualofPublic/nternational Law. Nueva York: McMillan, St. Martin's Press, 1968. Versión castellana: Manual de Derecho internacional público.MéxicoD.F.:FondodeCulturaEconómico,primeraediciónenespañol1973,tercerareimpresión1985, pp. 506-568, p. 533.

66 Soloenúltimoextremounamedidadeestetipopuedeadoptarseencircunstanciastalesqueexcluyanlailicitud del hecho del Estado, en el sentido empleado por la CDI en el capítulo V de la primera parte de su proyecto de artículossobreresponsabilidaddelEstadoporhechosinternacionalmenteilícitos,yque,enconsecuencia,no constituiría la violación de obligaciones y no daría lugar a la responsabilidad internacional del Estado. 